\title{
Seismic vulnerability assessment of a high-rise molten-salt solar tower based on incremental dynamic analysis
}

\author{
Weiwei $\mathrm{Sun}^{1,2}$, Dina $\mathrm{D}^{\prime} \mathrm{Ayala}^{2}$, Jinxing $\mathrm{Fu}^{1}$, Wentao $\mathrm{Gu}^{3}$, and Jun Feng, ${ }^{4}{ }^{*}$ \\ ${ }^{1}$ Nanjing University of Science and Technology, Department of Civil Engineering, 210094 Nanjing, China \\ ${ }^{2}$ University College London, Department of Civil, Environmental and Geomatic Engineering, WC1E 6BT London, United Kingdom \\ ${ }^{3}$ China Energy Engineering Group Jiangsu Power Design Institute Co., Ltd, 211102 Nanjing, China \\ ${ }^{4}$ Nanjing University of Science and Technology, National Key Laboratory of Transient Physics, 210094 Nanjing, China
}

\begin{abstract}
This paper investigates the seismic performance of a high-rise molten-salt solar tower by finite element modelling. The integrated and separated models for solar tower based on the concrete damage plastic model are validated by matching the behaviour of similar reinforced concrete chimney specimens. The modal analysis demonstrates the first four modes of the solar tower are translational vibration. Seismic simulations are developed through the incremental dynamic analysis. The most disadvantageous position of the tower is all concentrated in the opening section under multidirectional seismic excitations. The top displacement of the tower under bidirectional and three-directional earthquake actions is larger than that under unidirectional earthquake actions. The results of the seismic vulnerability assessment show that when the PGA equals to $0.035 \mathrm{~g}$, the tower will be intact; when the PGA equals to $0.1 \mathrm{~g}$ (design peak ground acceleration), the probability of the moderate damage state is within $1.5 \%$; when the PGA equals to $0.22 \mathrm{~g}$ (maximum considered earthquake), the probability of the destruction state is below $0.7 \%$. The seismic partitioned fragility analysis of the tower under multidirectional earthquake excitations illustrates that there are two peaks in the vulnerability surfaces. The anti-collapse analysis indicates the tower has a good seismic performance under multidirectional seismic excitations.
\end{abstract}

\section{Introduction}

Solar power is the fastest-growing source of renewable energy. A large number of molten-salt power tower plants have been built in recent years [1]. A tubular-type solar receiver is installed at the top of the molten-salt power tower to receive solar energy from a field of heliostats [2]. Tower power generation technology has been proved to be effective, reliable and practical [3]. As the core structure of the solar power station, a solar tower can use concrete or steel structures and the highrise tower is more suitable for adopting the concrete structure due to the low cost [2]. It is a fact that there are many similarities between the concrete tower and the concrete chimney, therefore the structural design of the tower usually refers to the chimney codes [4-6]. But the most significant difference between these two structures is that there is a receiver of huge mass at the top of the tower [7].

Many researchers have carried out the seismic performance research of the high-rising structures with reinforced concrete shell. Wilson conducted an experimental study on the cyclic behaviour of reinforced concrete chimney sections with and without openings [89]. Huang et al. performed a pushover analysis of a collapsed reinforced concrete chimney to find a cause of the failure [10]. Zhou et al. conducted a seismic partitioned fragility analysis of a 240 -m-high reinforced concrete chimney [11]. Deng et al. investigated the seismic effects of a solar receiver installed on concrete towers with different fundamental periods [12]. Lin et al. simulated the collapse of a cooling tower and the ground motion was based on the principle of wave superposition [13]. Balla et al. assessed the seismic amplification factors for the roof-mounted solar tower [14]. Preciado conducted the failure modes simulation and seismic vulnerability analysis of European ancient masonry towers based on nonlinear static pushover analyses [15].

To sum up, there are relatively few investigations on the seismic performance of the high-rise solar tower. In this paper, the Incremental Dynamic Analysis (IDA) of the solar tower under multidirectional earthquake actions is conducted [16-17], and the seismic vulnerability analysis and partitioned fragility analysis of the tower are carried out to obtain the curves and surfaces of failure probability [18].

\section{Finite element model of the solar tower}

\subsection{Verification of finite element model}

* Corresponding author: jun.feng@njust.edu.cn 
It is necessary to validate the finite element model before carrying out seismic simulations of the solar tower. Due to the fact that the experiment of the solar tower is very rare at present, this paper selects a similar experiment of the concrete chimney in references [8-9] as model verification, whereby six reinforced concrete chimney specimens are divided into two types: with and without openings. Four specimens are without openings (unit1unit4) and the other two are with openings (unit5 and unit6). All specimens with the same outer diameter of $1200 \mathrm{~mm}$ are composed of a steel tube for force transmission and a concrete tube for the test. The steel tube is $2450-\mathrm{mm}$-long and 30 -mm-thick. The typical length of the concrete tube is $2115 \mathrm{~mm}$ and the thickness is $30 \mathrm{~mm}$ or $40 \mathrm{~mm}$. The concrete compressive strength is about $40 \mathrm{MPa}$ while the yield strength of the steel bars varies greatly because some of them are heat treated. Several steel plates are used to connect the steel tube and the concrete tube, and the bottom of the concrete tube is constrained. The axial force of $226 \mathrm{kN}$ is applied to the top of the steel tube by two prestressed tendons. The hysteretic curves of the concrete tube are obtained by loading cyclic displacement on the top of the steel tube and recording the top reaction force. Detailed parameters and processes of the test can be found in references [8-9].

ABAQUS software is used to build the finite element models for the chimney specimens. Two kinds of finite element models are established: the separated model and the integrated model. The S4R element is used for modeling both the concrete and steel tubes in the integrated models, and the diameter, spacing, and layout of the reinforcement are defined by Rebar command [19]. The concrete and steel tubes in the separated models are simulated by the C3D8R element, and the TRUSS element is utilized to model the reinforcement [19]. The basic material parameters of the concrete and reinforcement are consistent with those in reference [89]. The concrete damage plasticity model in ABAQUS is used to simulate the mechanical response and damage accumulation of concrete material. The elastic-plastic parameters of concrete include dilation angle, eccentricity, biaxial and uniaxial compressive strength ratio $\left(f_{b 0} / f_{c 0}\right)$, coefficient $k$ and viscosity parameter, and the specific values are shown in Table 1 . The yield stress vs. inelastic strain (compression and tension) of concrete is determined according to the appendix $\mathrm{C}$ of Chinese code for design of concrete structures GB 500102010[20]. The stress-strain curve of the reinforcement is bilinear, and the main parameters include the elastic modulus $E_{0}$, the yield strength $f_{y}$ and the equivalent elastic modulus in the yield stage $E\left(E=0.01 E_{0}\right)$. The steel tube is connected with the concrete tube by tie constraints, and all the nodes at the bottom of the concrete tube are fixed. The finite element models of the concrete chimney specimens are shown in Figure 1.

According to the cyclic loading history of the test, the displacement is applied to the top of the steel tube after the axial force is applied, and the static analysis is performed. The hysteresis curves of the specimens from the finite element models are compared with test data, as presented in Figure 2. It can be seen that both the integrated and separated models can accurately simulate the damage evolution process of the concrete tubes. Because the modeling workload and calculation time of the integrated model are far less than those of the separated model, the subsequent IDA is based on the integrated model.

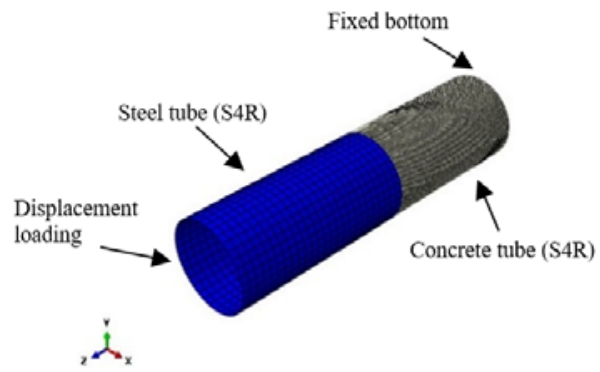

(a) Integrated model

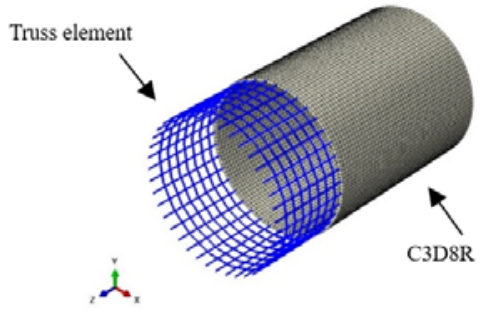

(b) Separated model (local)

Fig. 1. Finite element models of reinforced concrete chimney specimen

Table 1. Plastic parameters of concrete

\begin{tabular}{ccccc}
\hline Dilation angle & Eccentricity & $f_{b 0} / f_{c 0}$ & $k$ & Viscosity parameter \\
\hline $30^{\circ}$ & 0.1 & 1.16 & 0.6667 & 0.005 \\
\hline
\end{tabular}

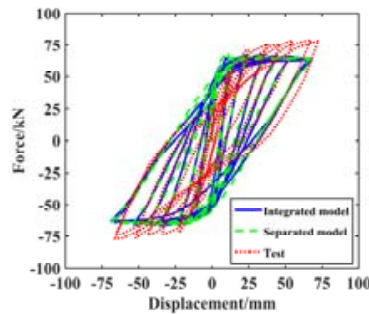

(a) Unit1

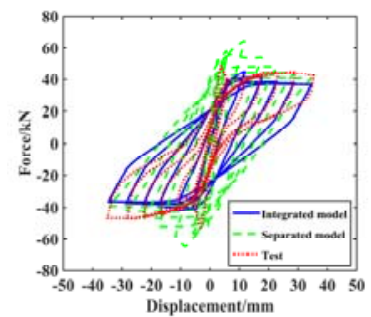

(c) Unit3

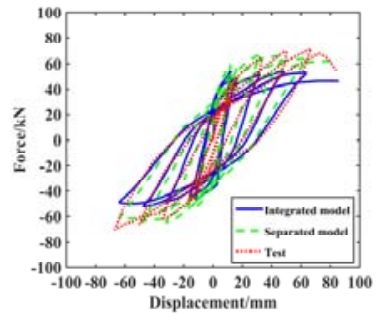

(e) Unit5

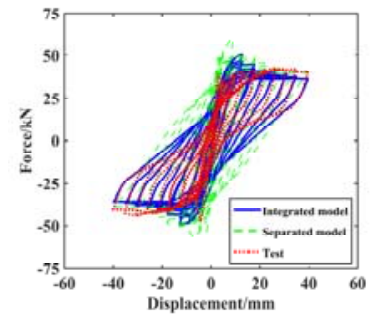

(b) Unit2

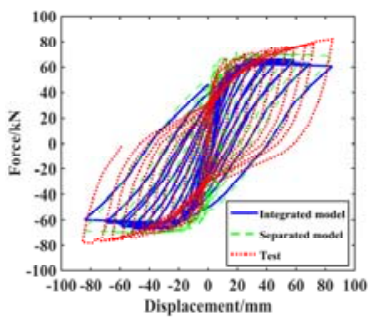

(d) Unit4

(f) Unit6

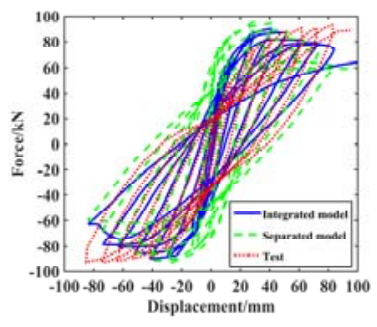

Fig. 2. Comparison of hysteretic curves 


\subsection{Basic information about the solar tower}

The total height of the solar tower is $225 \mathrm{~m}$, including a concrete tower with a height of $188 \mathrm{~m}$ and a receiver with a height of $37 \mathrm{~m}$ placed at top of the concrete tower. The receiver has a diameter of $25 \mathrm{~m}$ and a weight of 3825 tons. The outer diameter of the concrete tower $(18 \mathrm{~m})$ remains unchanged, the wall thickness varies from $900 \mathrm{~mm}$ to $450 \mathrm{~mm}$. The grade of concrete is mainly $\mathrm{C} 40$, and C30 is used at the top of the concrete tower, and the grade of steel reinforcement is HRB400 (symbol C) [20]. The section size and the reinforcement conditions of the concrete tower are shown in Table 2. The seismic fortification intensity is 7 with Site-classes II, and the design seismic group is Group 2 [21]. The design peak ground acceleration (PGA) equals $0.1 \mathrm{~g}$ (exceedance probability is $10 \%$ in 50 years). There is an 8 -m-wide and 20-m-high opening at the bottom of the tower, so both horizontal and vertical additional reinforcements are placed around the opening according to Chinese code for design of chimneys GB 50051-2013 [6]. The reinforced concrete slab foundation of the tower has a diameter of $32 \mathrm{~m}$ and a thickness of $3.8 \mathrm{~m}$.

Table 2. Parameters of the solar tower

\begin{tabular}{cccccc}
\hline $\begin{array}{c}\text { Elevation } \\
(\mathrm{m})\end{array}$ & $\begin{array}{c}\text { Wall } \\
\text { thicknss } \\
(\mathrm{mm})\end{array}$ & $\begin{array}{c}\text { Concrete } \\
\text { grade }\end{array}$ & $\begin{array}{c}\text { Outside } \\
\text { vertical } \\
\text { rebar }\end{array}$ & $\begin{array}{c}\text { Inside } \\
\text { vertical } \\
\text { rebar }\end{array}$ & $\begin{array}{c}\text { Internal and } \\
\text { external } \\
\text { circumferential } \\
\text { rebar }\end{array}$ \\
\hline 188 & 450 & $\mathrm{C} 30$ & $\mathrm{C} 18 @ 200$ & $\mathrm{C} 16 @ 200$ & $\mathrm{C} 18 @ 250$ \\
175 & 450 & $\mathrm{C} 30$ & $\mathrm{C} 18 @ 200$ & $\mathrm{C} 16 @ 200$ & $\mathrm{C} 18 @ 250$ \\
165 & 450 & $\mathrm{C} 30$ & $\mathrm{C} 18 @ 200$ & $\mathrm{C} 16 @ 200$ & $\mathrm{C} 18 @ 250$ \\
155 & 450 & $\mathrm{C} 30$ & $\mathrm{C} 18 @ 200$ & $\mathrm{C} 16 @ 200$ & $\mathrm{C} 18 @ 250$ \\
145 & 450 & $\mathrm{C} 30$ & $\mathrm{C} 18 @ 200$ & $\mathrm{C} 16 @ 200$ & $\mathrm{C} 18 @ 250$ \\
136 & 450 & $\mathrm{C} 30$ & $\mathrm{C} 20 @ 200$ & $\mathrm{C} 18 @ 200$ & $\mathrm{C} 20 @ 250$ \\
135 & 600 & $\mathrm{C} 40$ & $\mathrm{C} 20 @ 200$ & $\mathrm{C} 18 @ 200$ & $\mathrm{C} 20 @ 250$ \\
125 & 600 & $\mathrm{C} 40$ & $\mathrm{C} 20 @ 200$ & $\mathrm{C} 18 @ 200$ & $\mathrm{C} 20 @ 250$ \\
115 & 600 & $\mathrm{C} 40$ & $\mathrm{C} 20 @ 200$ & $\mathrm{C} 18 @ 200$ & $\mathrm{C} 20 @ 250$ \\
105 & 600 & $\mathrm{C} 40$ & $\mathrm{C} 20 @ 200$ & $\mathrm{C} 18 @ 200$ & $\mathrm{C} 20 @ 250$ \\
96 & 600 & $\mathrm{C} 40$ & $\mathrm{C} 22 @ 200$ & $\mathrm{C} 20 @ 200$ & $\mathrm{C} 22 @ 250$ \\
95 & 700 & $\mathrm{C} 40$ & $\mathrm{C} 22 @ 200$ & $\mathrm{C} 20 @ 200$ & $\mathrm{C} 22 @ 250$ \\
85 & 700 & $\mathrm{C} 40$ & $\mathrm{C} 22 @ 200$ & $\mathrm{C} 20 @ 200$ & $\mathrm{C} 22 @ 250$ \\
75 & 700 & $\mathrm{C} 40$ & $\mathrm{C} 22 @ 200$ & $\mathrm{C} 20 @ 200$ & $\mathrm{C} 22 @ 250$ \\
65 & 700 & $\mathrm{C} 40$ & $\mathrm{C} 22 @ 200$ & $\mathrm{C} 20 @ 200$ & $\mathrm{C} 22 @ 250$ \\
56 & 700 & $\mathrm{C} 40$ & $\mathrm{C} 25 @ 200$ & $\mathrm{C} 20 @ 200$ & $\mathrm{C} 25 @ 250$ \\
55 & 800 & $\mathrm{C} 40$ & $\mathrm{C} 25 @ 200$ & $\mathrm{C} 20 @ 200$ & $\mathrm{C} 25 @ 250$ \\
45 & 800 & $\mathrm{C} 40$ & $\mathrm{C} 25 @ 200$ & $\mathrm{C} 20 @ 200$ & $\mathrm{C} 25 @ 250$ \\
35 & 800 & $\mathrm{C} 40$ & $\mathrm{C} 25 @ 200$ & $\mathrm{C} 20 @ 200$ & $\mathrm{C} 25 @ 250$ \\
26 & 800 & $\mathrm{C} 40$ & $\mathrm{C} 25 @ 200$ & $\mathrm{C} 22 @ 200$ & $\mathrm{C} 25 @ 250$ \\
25 & 900 & $\mathrm{C} 40$ & $\mathrm{C} 25 @ 200$ & $\mathrm{C} 22 @ 200$ & $\mathrm{C} 25 @ 250$ \\
15 & 900 & $\mathrm{C} 40$ & $\mathrm{C} 25 @ 200$ & $\mathrm{C} 22 @ 200$ & $\mathrm{C} 25 @ 250$ \\
5 & 900 & $\mathrm{C} 40$ & $\mathrm{C} 25 @ 200$ & $\mathrm{C} 22 @ 200$ & $\mathrm{C} 25 @ 250$ \\
0 & 900 & $\mathrm{C} 40$ & $\mathrm{C} 25 @ 200$ & $\mathrm{C} 22 @ 200$ & $\mathrm{C} 25 @ 250$ \\
\hline & & & & & \\
\hline & & &
\end{tabular}

Table 3. Concrete parameters

\begin{tabular}{ccccc}
\hline $\begin{array}{c}\text { Concrete } \\
\text { grade }\end{array}$ & $\begin{array}{c}\text { Modulus of } \\
\text { elasticity } \\
(\mathrm{GPa})\end{array}$ & $\begin{array}{c}\text { Axial } \\
\text { compressive } \\
\text { strength } \\
(\mathrm{MPa})\end{array}$ & $\begin{array}{c}\text { Axial } \\
\text { tensile } \\
\text { strength } \\
(\mathrm{MPa})\end{array}$ & $\begin{array}{c}\text { Poisson's } \\
\text { ratio }\end{array}$ \\
\hline C30 & 30 & 20.1 & 2.01 & 0.2 \\
C40 & 32.5 & 26.8 & 2.39 & 0.2 \\
\hline
\end{tabular}

Table 4. Reinforcement parameters

\begin{tabular}{ccccc}
\hline $\begin{array}{c}\text { Reinforcement } \\
\text { grade }\end{array}$ & $\begin{array}{c}\text { Modulus of } \\
\text { elasticity } \\
(\mathrm{GPa})\end{array}$ & $\begin{array}{c}\text { Yield } \\
\text { strength } \\
(\mathrm{MPa})\end{array}$ & $\begin{array}{c}\text { Ultimate } \\
\text { strength } \\
(\mathrm{MPa})\end{array}$ & $\begin{array}{c}\text { Poisson's } \\
\text { ratio }\end{array}$ \\
\hline HRB400 & 200 & 400 & 540 & 0.3 \\
\hline
\end{tabular}

\subsection{Establishment of finite element model}

The modeling method of the concrete and reinforcement in the finite element model of the solar tower (see Figure 3 ) is consistent with foregoing integrated finite element model of the chimney. The receiver is set as a rigid body and tie constraints are assigned between the receiver and the tower. The strength parameters of the concrete and reinforcement are in accordance with the characteristic values of tensile and compressive strength in GB 500102010, as indicated in Tables 3 and 4 [20]. The Rayleigh damping is used to consider the damping effect of the tower. The damping ratio of the concrete is 0.05 , and that of the reinforcement is $0.02[6,21]$.

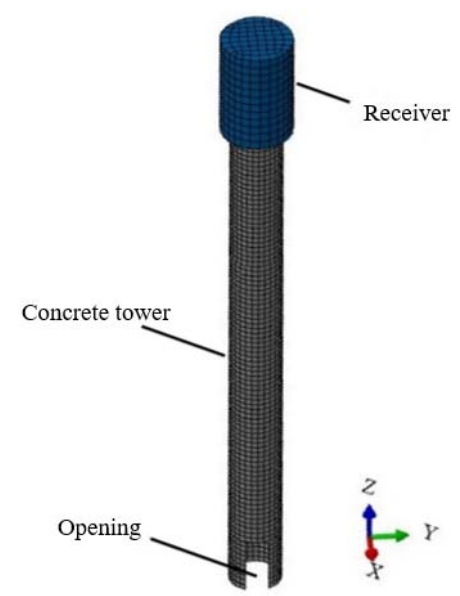

Fig. 3. Finite element model of the solar tower
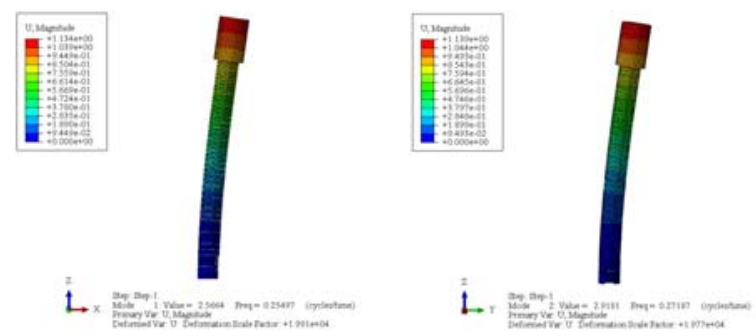

(a) $T_{l}=3.992 \mathrm{~s}$ (X direction)
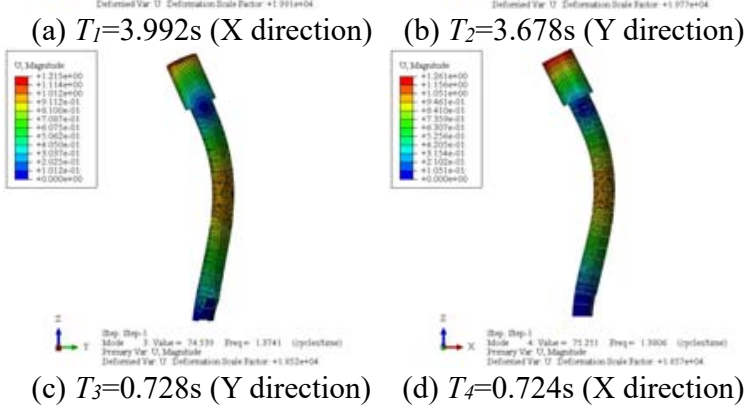

(d) $T_{4}=0.724 \mathrm{~s}$ (X direction)

Fig. 4. First four modes of the solar tower

\subsection{Modal analysis}

As illustrated in Figure 4, the first four modes of vibration are all translational, in which the first and 
fourth modes of vibration are in the $\mathrm{X}$ direction, and the second and third modes of vibration are in the $\mathrm{Y}$ direction. The period of the first mode is slightly larger than that of the second mode due to the large opening at the bottom of the tower, while the third and fourth modes are very close. The effective participation mass factors of the first four modes in the $\mathrm{X}$ and $\mathrm{Y}$ direction are close to $80 \%$ [22]. The fifth mode of vibration is torsional $\left(T_{5}=0.4430\right)$, and the ratio of the torsioncontrolled first period to the translation-controlled first period $\left(T_{5} / T_{l}=0.1110\right)$ indicates that the torsional stiffness of the tower is large. The first vertical vibration is the ninth mode, and its effective participation mass factor in the $\mathrm{Z}$ direction is more than $70 \%$ [22].

\section{IDA analysis of the solar tower}

\subsection{Preparation for the IDA}

It needs to choose Intensity Measure (IM), Damage Measure (DM), ground motions and carry out amplitude modulation of ground motions before the IDA. According to the research of high-rise chimney [11,23], the PGA is selected as the IM and the DMs choose the compressive strain of the concrete and the tensile strain of the reinforcement. According to reference [24], the earthquake damage of the tower is classified into 5 levels, which are: basically intact (DS1), minor damage (DS2), moderate damage (DS3), severe damage (DS4), destruction (DS5). In order to determine the damage level of the tower, four corresponding Limit States (LS) LS1-LS4 are needed to be defined, as indicated in Table 5 [11].

The selection of ground motions has a great influence on the IDA results. The seismic design response spectrum is taken as the target spectrum so that the average response spectrum of the selected ground motions is as close as possible to the target spectrum. According to the above principles, this paper selects eleven seismic records from the database of the Pacific Earthquake Engineering Research Center (PEER), as shown in Table 6 . The target spectrum and the response spectra of eleven ground motions are shown in Figure 5. After getting the appropriate ground motions, it is necessary to scale the IMs in the original record of ground motions [25].

Table 5. Limit state value

\begin{tabular}{ccc}
\hline $\begin{array}{c}\text { Limit } \\
\text { state }\end{array}$ & $\begin{array}{c}\text { Compressive strain of } \\
\text { concrete }\end{array}$ & $\begin{array}{c}\text { Tensile strain of } \\
\text { reinforcement }\end{array}$ \\
\hline LS1 & $\varepsilon_{c 1}=0.002$ & $\varepsilon_{s 1}=0.002$ \\
LS2 & $\varepsilon_{c 2}=0.0035$ & $\varepsilon_{s 2}=0.01$ \\
LS3 & $\varepsilon_{c 3}=0.005$ & $\varepsilon_{s 3}=0.03$ \\
LS4 & $\varepsilon_{c 4}=0.008$ & $\varepsilon_{s 4}=0.05$ \\
\hline
\end{tabular}

Table 6. Selected ground motions

\begin{tabular}{cccc}
\hline Number & Event & Year & $\begin{array}{c}\text { Moment } \\
\text { magnitude }\end{array}$ \\
\hline RSN15 & Kern County & 1952 & 7.36 \\
RSN93 & San Fernando & 1971 & 6.61 \\
RSN137 & Tabas Iran & 1978 & 7.35 \\
RSN140 & Tabas_Iran & 1978 & 7.35 \\
RSN164 & Imperial Valley-06 & 1979 & 6.53 \\
RSN167 & Imperial Valley-06 & 1979 & 6.53
\end{tabular}

\begin{tabular}{lccc} 
RSN289 & Irpinia_Italy-01 & 1980 & 6.9 \\
RSN300 & Irpinia_Italy-01 & 1980 & 6.2 \\
RSN324 & Coalinga-01 & 1983 & 6.36 \\
RSN341 & Coalinga-01 & 1983 & 6.36 \\
RSN832 & Landers & 1992 & 7.29 \\
\hline
\end{tabular}

\subsection{IDA curves of the tower under multidirectional seismic excitations}

The ground motions are applied in $\mathrm{X}$ direction, $\mathrm{X}$ direction $+0.85 \times \mathrm{Y}$ direction, $\mathrm{X}$ direction $+0.85 \times \mathrm{Y}$ direction $+0.65 \times \mathrm{Z}$ direction, respectively [21]. Due to the huge amount of data obtained from time history analysis, it compiles the Python script to get the strain of the concrete and reinforcement. The results show that when the strain of the concrete reaches the limit state, the reinforcement has not yet reached the corresponding limit state. This is consistent with the results of the reinforced concrete chimney shell $[11,23]$, so the compressive strain of the concrete is taken as the DM of the solar tower directly in the subsequent research.

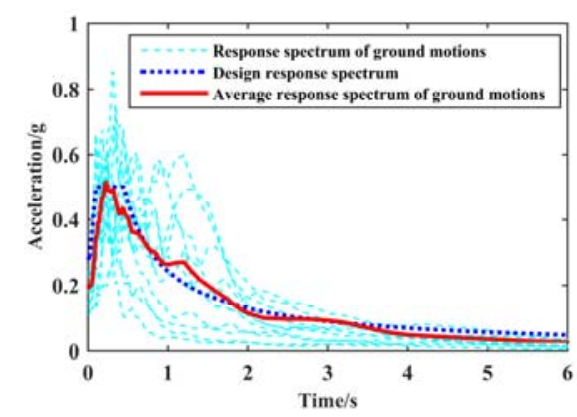

Fig.5. Design response spectrum and average response spectrum of selected ground motions

Figure 6 depicts the IDA curves of the tower under multidirectional seismic excitations. The $\mathrm{X}$-axis represents the logarithm value of PGA, and the Y-axis denotes the logarithm value of the ratio of maximum strain to limit state strain (LS4). Table 7 summarizes the equations for fitting curves of IDA data (least square) corresponding to each limit state under multidirectional earthquake actions.

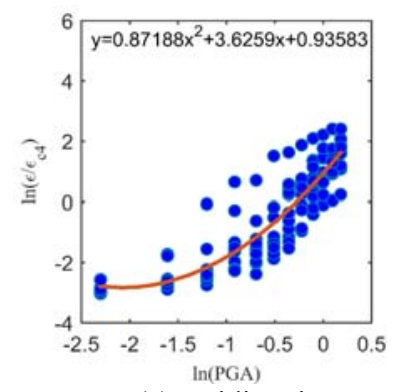

(a) Unidirection

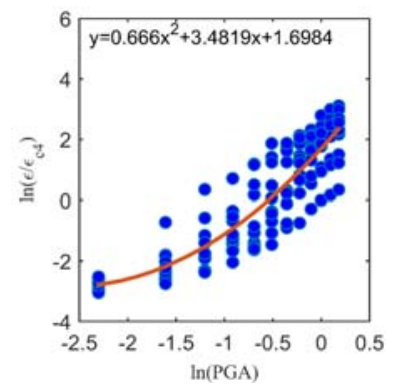

(b) Bidirection 


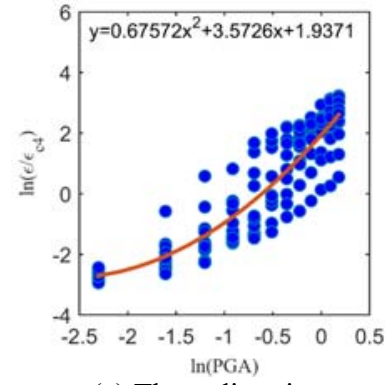

(c) Three direction

Fig.6. IDA curves of the solar tower under multidirectional seismic excitations

\subsection{Most disadvantageous position of the solar tower}

The most disadvantageous position is also worthy of attention in the seismic performance analysis of the tower. The location where the maximum concrete strain occurs is considered as the most unfavorable location, as illustrated in Figure 7. The number of ground motions is the X-axis, the PGA is the Y-axis, and the height of the tower is the Z-axis. Because the most disadvantageous position is all concentrated near the opening (see Figure 8 ), the Z-axis only shows the $25 \mathrm{~m}$ height at the bottom of the tower.

Table 7. Fitting curve expressions of IDA data

\begin{tabular}{ccc}
\hline Direction of ground motions & Limit state & $\begin{array}{c}\text { The equations for fitting } \\
\text { curves }\end{array}$ \\
\hline \multirow{4}{*}{ Unidirection } & LS1 & $0.8719 x^{2}+3.6259 x+2.3221$ \\
& LS2 & $0.8719 x^{2}+3.6259 x+1.7625$ \\
& LS3 & $0.8719 x^{2}+3.6259 x+1.4058$ \\
& LS4 & $0.8719 x^{2}+3.6259 x+0.9358$ \\
Bidirection & LS1 & $0.6660 x^{2}+3.4819 x+3.0847$ \\
& LS2 & $0.6660 x^{2}+3.4819 x+2.5250$ \\
& LS3 & $0.6660 x^{2}+3.4819 x+2.1684$ \\
Three direction & LS4 & $0.6660 x^{2}+3.4819 x+1.6984$ \\
& LS1 & $0.6757 x^{2}+3.5726 x+3.3234$ \\
& LS2 & $0.6757 x^{2}+3.5726 x+2.7638$ \\
& LS3 & $0.6757 x^{2}+3.5726 x+2.4071$ \\
& LS4 & $0.6757 x^{2}+3.5726 x+1.9371$ \\
\hline
\end{tabular}

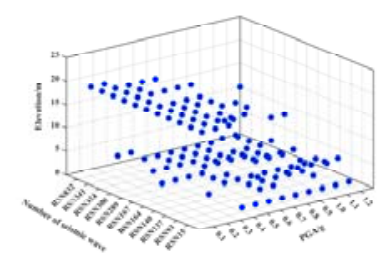

(a) Unidirection

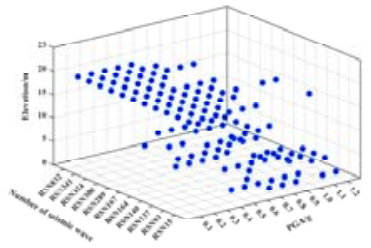

(b) Bidirection

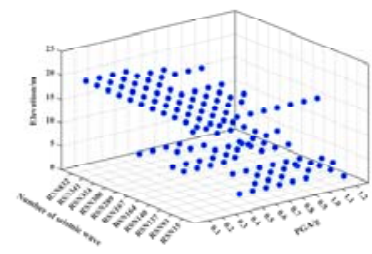

(c) Three direction

Fig.7. The most disadvantageous position of the solar tower under multidirectional seismic excitations

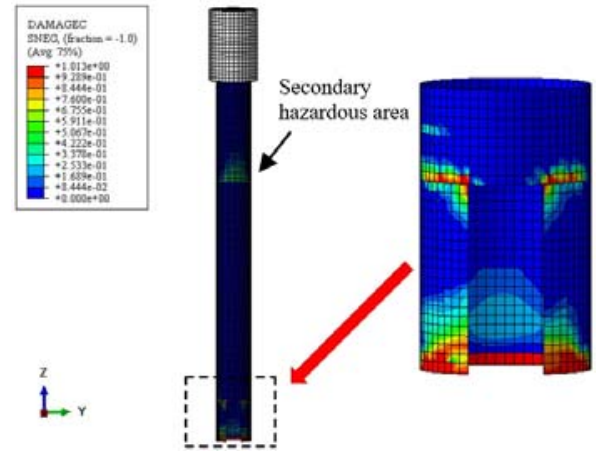

Fig.8. Compression damage (DAMAGEC) of the solar tower under earthquake action

\subsection{Top displacement of the solar tower}

The displacement of the receiver is an important design index of the solar tower, which directly affects the efficiency and stability of photothermal power generation. Based on the results of IDA, the top displacement of the tower (center of the receiver) under multidirectional seismic excitations is summarized, as shown in Figure 9. When the PGA is less than $0.5 \mathrm{~g}$, the top displacement of the tower is basically within $1 \mathrm{~m}$, and the displacement increases linearly with the increase of the PGA. When the PGA is greater than $0.8 \mathrm{~g}$, the top displacement increases rapidly and becomes very discrete. The influence of seismic wave characteristics on the response of the tower begins to appear, which also shows that the plastic deformation of the tower is large at this time. The top displacement under the bidirectional and three-dimensional earthquake actions is larger than that under unidirectional earthquake actions.

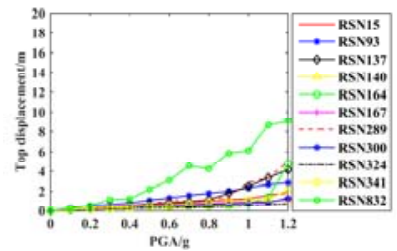

(a) Unidirection

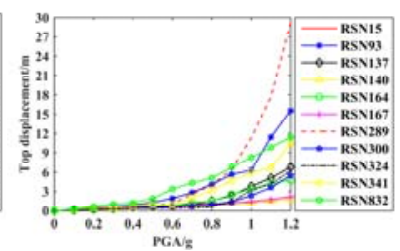

(b) Bidirection

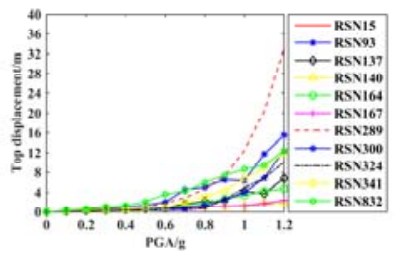

(c) Three direction

Fig.9. Top displacement of the solar tower under multidirectional seismic excitations 


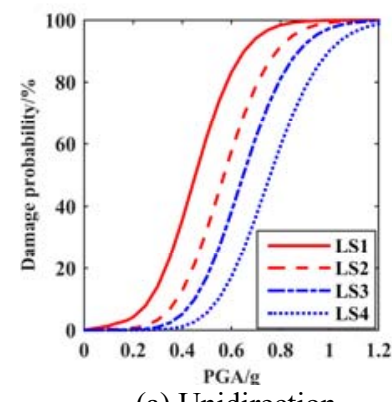

(a) Unidirection

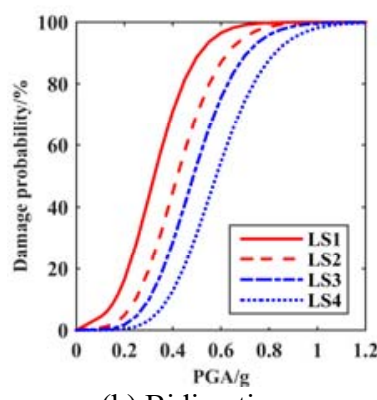

(b) Bidirection

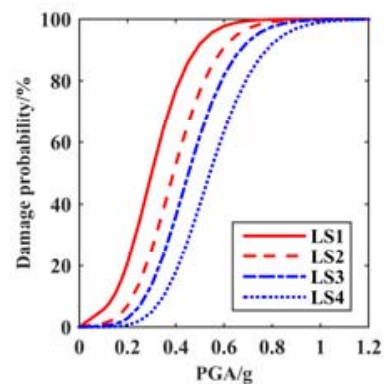

(c) Three direction

Fig.10 Vulnerability curves of the solar tower under multidirectional earthquake actions

\section{Vulnerability analysis of the solar tower}

Figure 10 illustrates the vulnerability curves of the tower under multidirectional earthquake actions by processing the IDA data [26]. When the PGA equals to $0.035 \mathrm{~g}$ (exceedance probability is $63 \%$ in 50 years), the exceedance probability of LS1 under multidirectional seismic excitations is close to $0 \%$, which states clearly that the tower will be intact. When the PGA equals to $0.10 \mathrm{~g}$ (the design peak ground acceleration), the exceedance probability of LS2 under multidirectional earthquakes is within $1.5 \%$, which implies the tower has a small probability of moderate damage. When the tower is subjected to Maximum Considered Earthquake (MCE), the PGA equals to $0.22 \mathrm{~g}$ (exceedance probability is $2-3 \%$ in 50 years), and the exceedance probability of LS4 under multidirectional earthquakes is within $0.70 \%$, which indicates no collapse under rare earthquake. When the PGA is between $0.4 \mathrm{~g}$ and $0.8 \mathrm{~g}$, the difference of the exceedance probabilities of LS1-LS4 under the action of unidirectional, bidirectional and three-directional earthquakes is more obvious. It is clear that the tower under three-dimensional earthquake action is the most disadvantageous.

Table 8. The zones of the solar tower

\begin{tabular}{ccccc}
\hline Number & P1 & P2 & P3 & P4 \\
\hline Elevation $(\mathrm{m})$ & $0-10$ & $10-20$ & $20-40$ & $40-60$ \\
\hline Number & P5 & P6 & P7 & P8 \\
\hline Elevation $(\mathrm{m})$ & $60-80$ & $80-100$ & $100-120$ & $120-140$ \\
\hline Number & P9 & P10 & P11 & \\
\hline Elevation $(\mathrm{m})$ & $140-160$ & $160-180$ & $180-188$ & \\
\hline
\end{tabular}

5 Seismic partitioned fragility analysis
The seismic partitioned fragility analysis is an extension and supplement of the vulnerability analysis. The concrete tower is divided into 11 zones as indicated in Table 8. The partitioned fragility analysis process is similar to the vulnerability analysis. For clarity, the vulnerability surfaces of the tower under multidirectional earthquake excitations are illustrated in Figures 11-13. The X-axis represents the PGA, the Y-axis denotes the elevation of the tower, and the Z-axis indicates the damage probability of each zone. There are two peaks in all the vulnerability surfaces, among which the large peak indicates the most vulnerable position of the tower within the opening zone (see Figure 7). For the small peak, its location is fixed at a height of about $140 \mathrm{~m}$ (see Figure 8), and the peak value decreases from LS1 to LS4. The risk of this zone is relatively less than that of the opening zone.

\section{Anti-collapse analysis}

According to the anti-collapse analysis method in the ATC-63 report [27], the collapse resistance of the tower is analyzed quantitatively. It is measured by the Collapse Margin Ratio (CMR), as shown in Equation (1).

$$
C M R=\frac{I M_{50 \%}}{I M_{M C E}}
$$

Where $I M_{50 \%}$ indicates the IM that causes $50 \%$ probability of collapse; $I M_{M C E}$ denotes the IM under MCE.

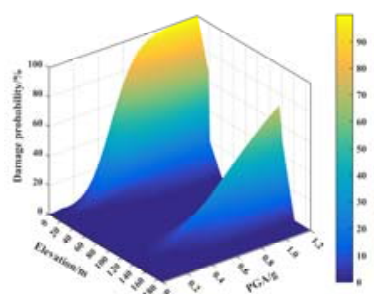

(a) LS1

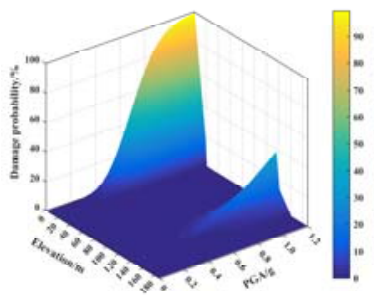

(c) LS3

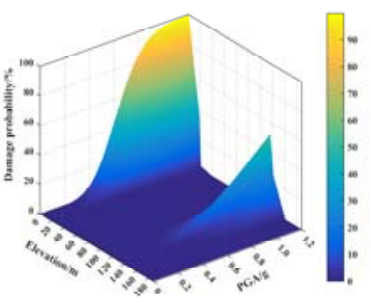

(b) LS2

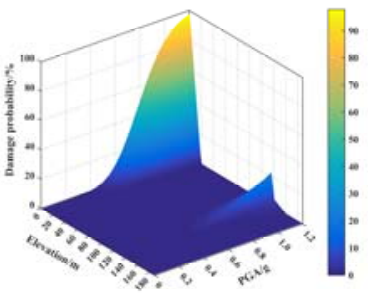

(d) LS4
Fig.11. Vulnerability surfaces of the solar tower under unidirectional seismic excitations

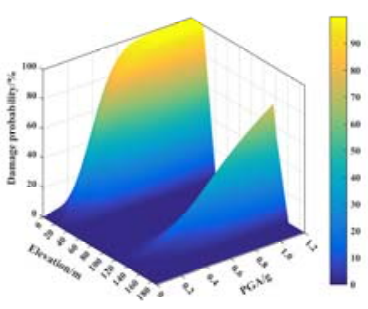

(a) LS1

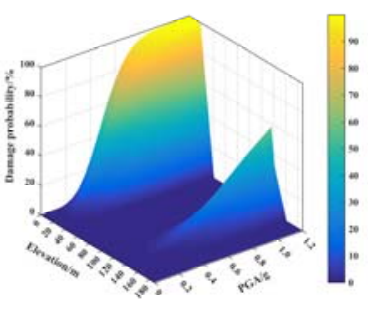

(b) LS2 
(c) LS3

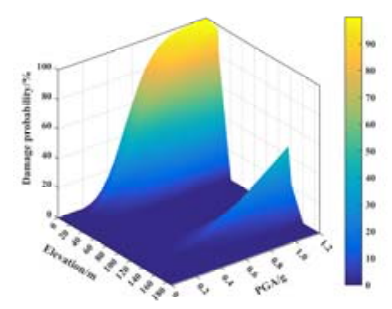

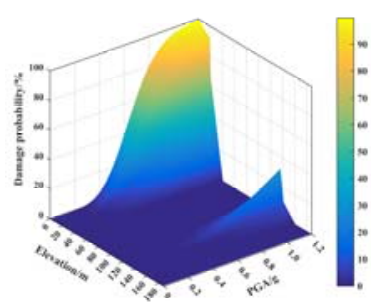

(d) LS4
Fig.12. Vulnerability surfaces of the solar tower under bidirectional seismic excitations

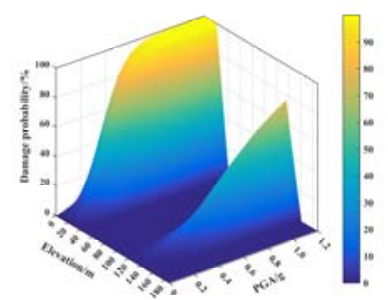

(a) LS1

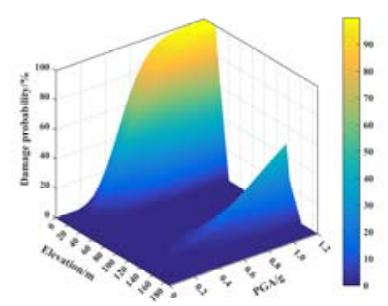

(c) LS3

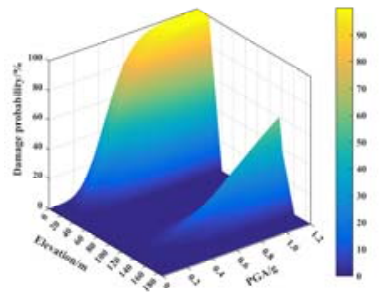

(b) LS2

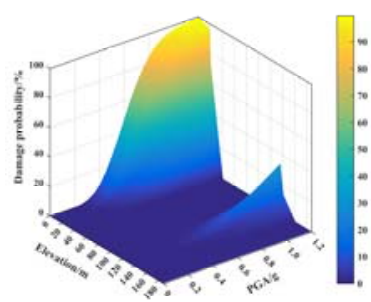

(d) LS4
Fig.13. Vulnerability surfaces of the solar tower under threedirectional seismic excitations

The PGA of MCE for seismic fortification intensity 7 is $0.22 \mathrm{~g}$. According to the vulnerability curves, the $I M_{50 \%}$ under unidirectional, bidirectional and three-directional earthquakes is $0.759 \mathrm{~g}, 0.580 \mathrm{~g}$ and $0.542 \mathrm{~g}$, respectively. The corresponding CMR is 3.45, 2.64 and 2.46, respectively, which indicates that the tower has a good seismic performance.

\section{Conclusions}

In this study, seismic vulnerability assessment of a highrise molten-salt solar tower is conducted by incremental dynamic analysis. The following conclusions are obtained:

1) The comparison between the test results and the finite element analysis results shows that the integrated and separated finite element models based on the concrete damage plastic model can accurately simulate the damage evolution process of the reinforced concrete tubes.

2) The first four modes of the tower are all translational vibration. Due to a large opening at the bottom of the collector, the period of the first mode is slightly larger than that of the second mode, and the third mode is very close to the fourth mode. The effective participation mass factors of the first four modes in the $X$ and $\mathrm{Y}$ directions are close to $80 \%$. The fifth mode is torsional vibration. The first vertical vibration is the ninth mode, and its effective participation mass factor in the $\mathrm{Z}$ direction is more than $70 \%$.

3) The most disadvantageous position of the tower is all concentrated in the opening zone. Under the bidirectional and three-directional earthquake actions, the top displacement is larger than that under the unidirectional earthquake actions.

4) The vulnerability analysis of the tower under multidirectional seismic excitations shows that when the PGA equals to $0.035 \mathrm{~g}$, the exceedance probability of LS1 are close to $0 \%$; when the PGA equals to $0.1 \mathrm{~g}$, the exceedance probability of LS2 is within $1.5 \%$; when the PGA equals to $0.22 \mathrm{~g}$, the exceedance probability of LS4 is within $0.70 \%$. The tower under the action of threedimensional earthquake is the most disadvantageous.

5) The partitioned fragility analysis of the tower shows that there are two peaks in the vulnerability surfaces of the tower under multidirectional earthquake actions. For the smaller peak, its location is fixed at a height of about $140 \mathrm{~m}$, and the peak value decreases from LS1 to LS4. The risk of this zone is relatively less than the opening zone. The anti-collapse analysis shows the tower of seismic performance is much better.

\section{Acknowledgments}

This work is supported by the National Natural Science Foundation of China (51308297 \& 11902161) and Nanjing Building System Project of China (Ks1717). Weiwei Sun thanks the financial support from the program of China Scholarships Council (No. 201806845044).

\section{References}

1. M. Atif, F. A. Al-Sulaiman, J, Energy. Eng 1444 (2018)

2. G. J. Kolb, An evaluation of possible nextgeneration high temperature molten-salt power towers (Sandia National Laboratories, Albuquerque, 2011)

3. H. E. Reilly, G. J. Kolb, An evaluation of moltensalt power towers including results of the solar two project (Sandia National Laboratories, Albuquerque, 2001)

4. ACI 307-08, Code Requirements for Reinforced Concrete Chimneys and Commentary (American Concrete Institute, Farmington Hills, 2008)

5. CICIND, Model Code for Concrete Chimneys - Part A: The Shell (commentary) (International Committee on Industrial Chimneys, Switzerland, 2001)

6. GB 50051-2013, Code for design of chimneys (China Planning Press, Beijing, 2013)

7. J. L. Wilson, Eng. Struct 251 (2003)

8. J. L. Wilson, Earthquake design and analysis of tall reinforced concrete chimneys (The University of Melbourne, Melbourne, 2000)

9. J. L. Wilson, Adv. Struct. Eng 123 (2009) 
10. W. Huang, P. L. Gould, R. Martinez, G. S. Johnson, Earthq. Eng. Struct. D 334 (2004)

11. C. Zhou, M. Tian, K. Guo, Struct. Des. Tall. Spec 28 1 (2019)

12. L. Deng, AIP. Conf. Proc 1734 (2016)

13. F. Lin, H.K. Ji, Y. N. Li, Z. X. Zuo, X. L. Gu, Y. Li, Soil. Dyn. Earthq. Eng 65 (2014)

14. P. Balla, Approximating the seismic amplification effects experienced by solar towers mounted on the rooftops of low-rise industrial buildings (California Polytechnic State University, San Luis Obispo, 2013)

15. A. Preciado, Eng. Fail. Anal 57 (2015)

16. D. Vamvatsikos, C. A. Cornell, Earthq. Eng. Struct D 313 (2002)

17. J.B. Mander, R.P. Dhakal, N. Mashiko, K. Solberg, Eng. Struct 2910 (2007)

18. S. Caprili, L. Nardini, W. Salvatore, B. Earthq. Eng 103 (2012)

19. M. Smith, ABAQUS/Standard User's Manual, Version 6.9 (Dassault Systèmes Simulia Corp, Providence, RI, 2009)
20. GB50010-2010, Code for design of concrete structures (China Architecture \& Building Press, Beijing, 2010)

21. GB 50011-2010, Code for seismic design of buildings (China Architecture \& Building Press, Beijing, 2010)

22. M. J. N. Priestley, S. Seible, G. M. Calvi, Seismic design and retrofit of bridges (John Wiley and Sons, New York, 1996)

23. C. Zhou, X. Zeng, Q. Pan, B. Liu, Struct. Des. Tall. Spec 246 (2015)

24. GB/T24335-2009, Classification of earthquake damage to buildings and special structures (Standards Press of China, Beijing, 2009)

25. K. R. Mackie, B. Stojadinovi, Fragility basis for California highway overpass bridge seismic decision making (PEER, University of California Berkeley, 2005)

26. Y. Pan, A. K. Agrawal, M. Ghosn, J. Bridge. Eng 12 6 (2007)

27. ATC-63, Quantification of building seismic performance factors (FEMA, Washington, 2009) 